\title{
A new high activity plasma cholinesterase variant
}

\author{
AMANDA KRAUSE, A B LANE, AND TREFOR JENKINS \\ From the MRC Human Ecogenetics Research Unit, Department of Human Genetics, School of Pathology, \\ South African Institute for Medical Research and University of the Witwatersrand, Johannesburg, South Africa.
}

SUMmaRY A South African Afrikaans speaking family is reported in which a new high activity plasma cholinesterase variant was found to occur in the mother and son. The variant has the same electrophoretic mobility as the 'usual' enzyme, but greater heat stability. Its higher specific activity is associated with a normal number of enzyme molecules. The variant may be inherited as a dominant trait, though its locus is uncertain.

The qualitative and quantitative characteristics of human plasma cholinesterase are determined by at least two autosomal loci, $E_{1}$ and $E_{2}$. The genetically determined variants at the $E_{1}$ locus include the $E_{1}^{*} a, E_{1}^{*} s, E_{1}^{*} f, E_{1}^{*} j$, and $E_{1}{ }^{*} k$ alleles. Their presence results in lower average activity than that observed in persons homozygous for the $E_{1}{ }^{*} u$ or 'usual' allele, which is the most common.

Two common $E_{2}$ locus alleles, the $E_{2}{ }^{*}+$ and $E_{2}{ }^{*}-$, are recognised. The presence of the rarer $E_{2}{ }^{*}+$ allele is associated with the production of an extra electrophoretically detected isozyme and an approximate $30 \%$ rise above normal activity. ${ }^{1}$ The commoner $E_{2}{ }^{*}-$ allele is silent. A number of rarer electrophoretic variants have also been described. ${ }^{2}{ }^{3}$ The extent of the increase in enzyme activity associated with the $E_{2}{ }^{*}+$ allele is variable, and the activity distribution of persons with the allele overlaps the normal distribution. The presence of the $E_{2}{ }^{*}+$ allele can, therefore, not be deduced on the basis of enzyme activity alone. ${ }^{1}$

In general, most rare alleles of enzyme encoding genes are associated with lower than normal enzyme activity which in some cases is the result of a relative deficiency in the amount of enzyme present. There are, however, a few variants which are associated with enhanced rather than diminished catalytic activity which is, at least in part, due to increased amounts of enzyme protein. The glucose 6 phosphate dehydrogenase variant, G6PD Hektoen, and the cholinesterase variant $E$ Cynthiana are two such variants. ${ }^{45}$

$E$ Cynthiana was first described by Neitlich ${ }^{6}$ and later reinvestigated and characterised by Yoshida and Motulsky. ${ }^{4}$ A second high activity cholinesterase

Received for publication 20 May 1987.

Revised version accepted for publication 30 September 1987. variant was reported by Delbruck and $\mathrm{Henkel}^{7}$ and appears to be identical to $E$ Cynthiana.

Although genetic factors are very important in determining plasma cholinesterase activity, various physiological, pathological, and pharmacological factors play an important role in contributing to the actual activity of the enzyme in a particular subject. At birth, cholinesterase levels are low, whereas between three and six years of life the mean enzyme activity is about $30 \%$ above the adult levels. It begins to decrease during the fifth year and continues to do so until the adult level is reached at puberty. The influence of sex on activity levels is less clear cut. Diseases associated with lowered cholinesterase activity include liver disease, myocardial infarction, and collagen diseases. Raised enzyme activity is associated with obesity, hyperlipidaemia, nodular goitre, essential hypertension, nephrosis, asthma, and alcoholism. ${ }^{8}$

This communication describes another cholinesterase variant which is associated with raised enzyme activity but which differs from $E$ Cynthiana in that the increased activity is not the result of increased amounts of enzyme protein.

\section{Materials and methods}

SUBJECTS

The proband was identified while screening the South African Afrikaner population for plasma cholinesterase variation. This population is descended from Dutch and German immigrants who settled at the Cape of Good Hope in 1652 and for the next 50 years or so, and from French Huguenots who joined them in 1688 . The relatively small number of founders underwent a striking population increase during the 18th century and the population is genetically noteworthy because of the presence of 
certain genes in unusually high frequencies, for example, porphyria variegata ${ }^{9}$ and familial hypercholesterolaemia. ${ }^{10}$

The proband was found to have approximately twice the normal amount of cholinesterase activity. Other members of her family were investigated and her son (aged 31 years) was also found to have increased activity. Both were healthy adults.

\section{CHOLINESTERASE DETERMINATION}

Enzyme activities were determined spectrophotometrically by the method of Kalow and Lindsay. ${ }^{11}$ Dibucaine numbers and fluoride numbers were obtained by the methods of Kalow and Genest ${ }^{12}$ and Harris and Whittaker, ${ }^{13}$ respectively, with the modifications proposed by Zsigmond et al. ${ }^{14}$

\section{ELECTROPHORESIS}

$E_{2}$ locus variation was determined by one dimensional starch gel electrophoresis performed according to the method of Harris et al. ${ }^{1}$ After electrophoresis, the gels were stained by the method of Stern and Lewis. ${ }^{15}$ Variation was confirmed by isoelectric focusing in a $\mathrm{pH}$ gradient of 3.5 to 5 in polyacrylamide gels, using the method described by Bark et $a^{16}$ for separating phosphoglucomutase isoenzymes. After isoelectric focusing, the polyacrylamide gels were stained in the same way as the starch gels.

MICHAELIS CONSTANT [ $\mathrm{K}_{\mathrm{m}}$ ] AND $\mathrm{V}_{\max }$

DETERMINATIONS

Michaelis constants and $V_{\max }$ values were estimated from least squares fits to data represented on standard Lineweaver-Burk plots.

\section{HEAT STABILITY DETERMINATION}

Serum samples were diluted 50 times with $0.3 \mathrm{~mol} / 1$ sodium phosphate at $\mathrm{pH} 7.4$ and then incubated for between five and 60 minutes at $52^{\circ} \mathrm{C}$, cooled in a $4^{\circ} \mathrm{C}$ water bath, and then assayed. Semilogarithmic plots of percentage of original activity remaining versus incubation time were used to estimate the half life values of the variant and usual cholinesterases under the conditions specified above.

\section{ACTIVE SITE TITRATIONS WITH DFP}

These were performed according to the method of Yoshida and Motulsky. ${ }^{4}$ Enzyme activity was determined in serum samples which had been incubated with various concentrations of diisopropyl fluorophosphate (DFP), a strong inhibitor of cholinesterase which binds irreversibly to a serine residue at the substrate binding site of the enzyme. ${ }^{1718}$

IMMUNOELECTROPHORESIS

Immunoelectrophoresis of plasma samples was car- ried out in $1 \%$ agarose gels by the method of Laurell. ${ }^{19}$ The gel and bridge buffer (pH 8.6) contained $0.075 \mathrm{~mol} / 1$ barbitol sodium, $0.0163 \mathrm{~mol} / 1$ barbital, $0.015 \mathrm{~mol} / \mathrm{l}$ sodium azide, and $1 \mathrm{mmol} / \mathrm{l}$ calcium lactate. Cholinesterase specific antibody, purchased from Calbiochem, was incorporated in the gels at a final dilution of 1 in 1000 . Electrophoresis was carried out at approximately $6^{\circ} \mathrm{C}$ overnight at a constant voltage of $5 \mathrm{~V} / \mathrm{cm}$. Nonprecipitated material was removed from the gels by soaking them in normal saline. The gels were then stained for cholinesterase activity by the same method as that used to detect the isozymes after electrophoresis.

\section{Results}

The pedigree of the family under investigation is shown in fig 1 and from the table it can be seen that serum from the proband (I.2) had about twice the normal level of cholinesterase activity, and that from her son (II.1) also had markedly raised activity. The dibucaine and fluoride numbers of the cholinesterase of the proband and her son are within the normal ranges. It should be noted that I.2 has the $\mathrm{C}_{5}+$ phenotype owing to the presence of an $E_{2}{ }^{*}+$ allele, while II.1 has the $\mathrm{C}_{5}-$ phenotype owing to homozygosity for the $E_{2}{ }^{*}-$ allele (fig 2). Both the proband and her son, however, appear to have the high activity variant. The variant enzyme did not show an abnormal electrophoretic mobility.

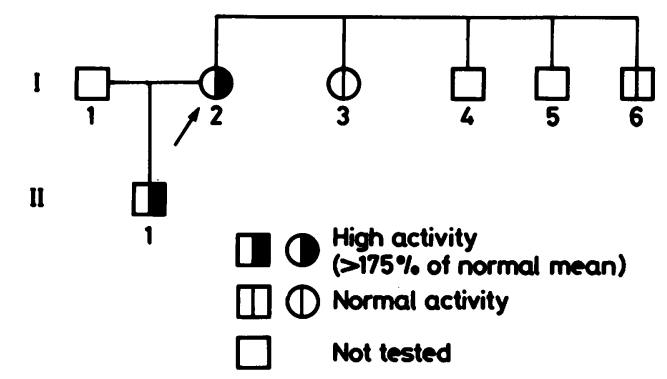

FIG 1 Pedigree of family with the high activity cholinesterase variant.

TABLE Cholinesterase and genotype data on family with high activity variant.

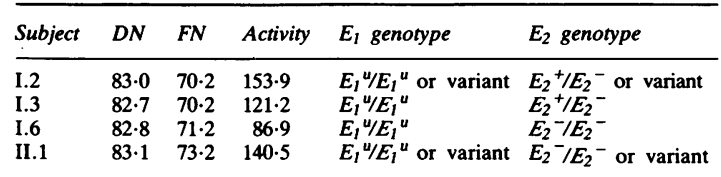


The variant enzyme's Michaelis constant $\left(\mathrm{K}_{\mathrm{m}}\right)$ for the substrate benzoylcholine chloride fell within the range of Michaelis constant estimates made for the enzyme from subjects with the usual phenotype. The presence or absence of the $E_{2}{ }^{*}+$ allele in random subjects made no apparent difference to the $\mathrm{K}_{\mathrm{m}}$ values.

The half life of the 'usual' enzyme was found to be $101 \pm 3.9$ minutes at $52^{\circ} \mathrm{C}(\mathrm{n}=3)$, while that of the 'variant' was 147 minutes under the conditions specified.

The results of the DFP active site titrations, plotted in the form of log of percentage activity remaining versus DFP concentration, produced linear curves. The activities of the 'usual' and 'variant' (and 'atypical') enzymes were decreased by the same percentage at each of the DFP concen- trations used. These results suggest that serum from the proband and her son contained the same concentration of substrate binding sites and therefore of enzyme molecules as each other and as normal subjects.

'Rocket' immunoelectrophoresis showed that plasma from the proband and her son contained similar amounts of immunoprecipitable cholinesterase to plasma from normal controls (fig 3 ). The slightly higher peak formed by the proband's plasma can probably be attributed to her $E_{2}{ }^{*}+$ allele, since the $E_{2}{ }^{*}+$ allele is known to cause an increase in cholinesterase protein. ${ }^{20} \mathrm{~A}$ serum sample from a subject who is believed to have the $E_{1}{ }^{*} j / E_{1}{ }^{*} s$ genotype (lane 6) can be seen to have a markedly lower concentration of immunoprecipitable cholinesterase.

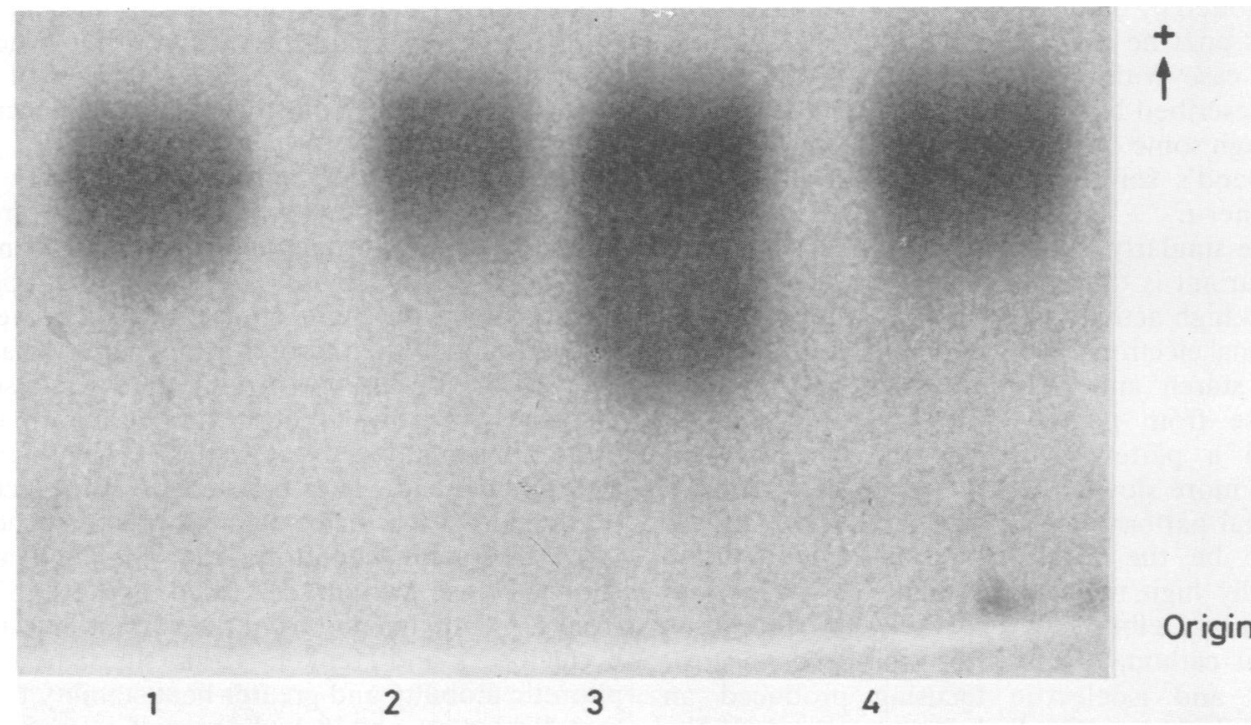

FIG 2 Zymogram used for $E_{2}$ phenotyping. Lanes 1 and 2=normal controls, lane 3=I.2 (proband), lane 4=II.1 (proband's son).
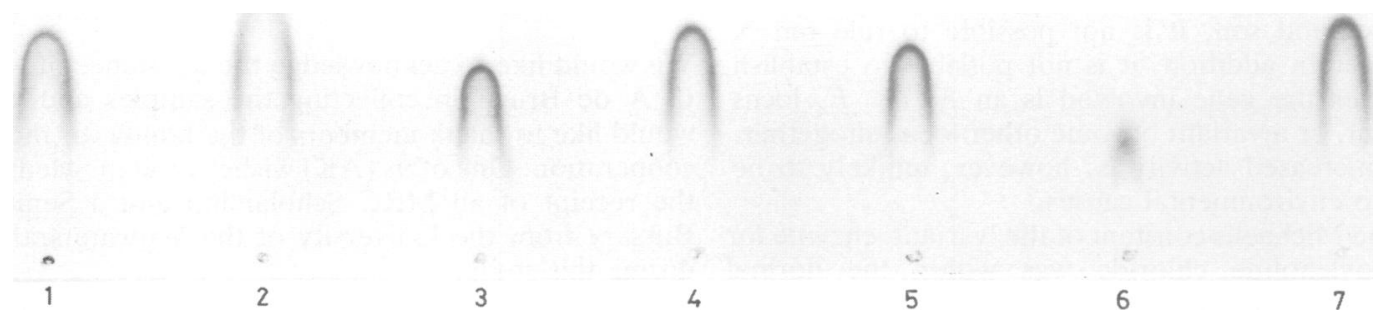

FIG 3 Rocket immunoelectrophoresis of plasma cholinesterase. Lanes 1, 3, 5, 7=normal controls, lane 2=I.2 (proband), lane 4=II.1 (proband's son), lane $6=$ subject believed to have the $E_{1}{ }^{*} j / E_{1}{ }^{*}$ s genotype. 


\section{Discussion}

The fact that the proband and her son both have activities which are approximately double those of the population mean (and greater than 2 SD above the population mean) suggests that the high activity trait was inherited by the son from his mother. As far as possible, non-genetic causes of raised $\mathrm{ChE}$ activity have been excluded. Blood samples could unfortunately not be obtained from the proband's father and no other members of the family who were tested showed abnormally raised activities. The slightly raised activity in I.3 can be attributed to the presence of an $E_{2}{ }^{*}+$ allele. The activity of $E$ Cynthiana was reported to be about two to three times normal, ${ }^{6}$ whereas the variant described by Delbruck and $\mathrm{Henkel}^{7}$ had three to four times normal activity.

Cholinesterase from the proband and her son were inhibited by dibucaine and fluoride to the same extent as enzyme from normal subjects. This was also the case with $E$ Cynthiana,${ }^{4}$ as well as the variant described by Delbruck and Henkel. ${ }^{7}$

Although some of the abnormally high activity of the proband's serum could be the result of the effect of her $E_{2}{ }^{*}+$ allele, the high activity in her son cannot be similarly explained.

This variant is different from the two previously described high activity variants in that it appears to have normal electrophoretic mobility. Electrophoresis in both starch and polyacrylamide gels of cholinesterase from persons who had $E$ Cynthiana produced a pattern with an extra band which migrated more slowly than the $\mathrm{C}_{4}$ and $\mathrm{C}_{5}$ bands of the normal pattern. The slower mobility band was found to be the result of an isozyme with an abnormally high molecular weight. ${ }^{46}$ The variant described by Delbruck and Henkel ${ }^{7}$ also showed an additional cathodal band after starch gel electrophoresis, and isoelectric focusing produced an abnormal pattern which had six extra bands in the pH 4.4 to 4.9 region of the gel.

The allele which produced the variant described here is apparently expressed as a dominant trait but since the only persons who appear to carry it are a mother and son, it is not possible to rule out $\mathrm{X}$ linkage. In addition, it is not possible to establish whether the gene involved is an $E_{1}$ or $E_{2}$ locus variant, or a variant of some other locus altogether. The increased activity is, however, unlikely to be due to environmental causes.

The Michaelis constant of the 'variant' enzyme for benzoylcholine chloride was within the normal range. The variant described by Delbruck and Henkel $^{7}$ appeared to have a normal $K_{m}$ for acetylthiocholine iodide, but no estimate for the $K_{m}$ for benzoylcholine was made. No kinetic studies were carried out on $E$ Cynthiana.

The variant enzyme studied here was shown to be more heat stable than the 'usual' enzyme at $52^{\circ} \mathrm{C}$. This is in contrast to the variant of Delbruck and Henkel, ${ }^{7}$ which showed similar heat stability to the 'usual' cholinesterase. Yoshida and Motulsky ${ }^{4}$ also found no differences in the in vitro stability of $E$ Cynthiana compared to the 'usual' enzyme. Although increased heat stability may be an indication of the overall stability of an enzyme, this is not necessarily the case, particularly as the in vitro determinations were carried out well above physiological temperatures.

The DFP and immunoprecipitation results indicate that the increased activity of the variant described here does not result from the presence of increased concentrations of cholinesterase protein, but rather from increased activity per active site. This is further evidence that the variant is different from $E$ Cynthiana and the variant of Delbruck and Henkel, ${ }^{7}$ since the increased activities of these appeared to result from the presence of increased amounts of enzyme.

Increased levels of enzyme activity may result from the presence of a hyperactive enzyme, from an increased rate of production of a structurally normal enzyme, from a decreased degradation rate, or from a combination of these effects. Although we have not determined the reason for the increased activity associated with this new variant, data would suggest that it results from the production, at a normal rate, of an abnormally active enzyme. $E$ Cynthiana, on the other hand, is attributed to the increased production of a structurally abnormal enzyme. ${ }^{4}$

We postulate, therefore, that the high activity cholinesterase variant described here is different from $E$ Cynthiana and from the variant investigated by Delbruck and Henkel. ${ }^{7}$ It has the same electrophoretic mobility and greater heat stability than the 'usual' enzyme, and its higher specific activity is not the result of the presence of an increased number of enzyme molecules. We propose that it be called $E$ Johannesburg after the city of residence of the person in whom it was found.

We would like to acknowledge the assistance of $\mathrm{Mr}$ G A de Bruyn in collecting the samples and we would like to thank members of the family for their cooperation. One of us (AK) wishes to acknowledge the receipt of an MRC Scholarship and a Senior Bursary from the University of the Witwatersrand during this study.

References
${ }^{1}$ Harris H, Hopkinson DA, Robson EB, Whittaker M. Genetical 
studies on a new variant of serum cholinesterase detected by electrophoresis. Ann Hum Genet 1963;26:359-82.

2 Ashton GC, Simpson NE. C5 types of serum cholinesterase in a Brazilian population. Am J Hum Genet 1966;18:438-47.

${ }^{3}$ Van Ros G, Druet R. Uncommon electrophoretic patterns of serum cholinesterase (pseudocholinesterase). Nature 1966; 212:543-4.

4 Yoshida A, Motulsky AG. A pseudocholinesterase variant (E Cynthiana) associated with elevated plasma enzyme activity. Am J Hum Genet 1969;21:486-97.

5 Yoshida A. Amino acid substitution (histidine to tyrosine) in a glucose-6-phosphate dehydrogenase variant (G6PD Hektoen) associated with overproduction. J Mol Biol 1970;52:483-90.

6 Neitlich HW. Increased plasma cholinesterase activity and succinylcholine resistance: a genetic variant. J Clin Invest 1966;45:380-7.

${ }^{7}$ Delbruck A, Henkel E. A rare genetically determined variant of pseudocholinesterase in two German families with high plasma enzyme activity. Eur J Biochem 1979;99:65-9.

8 Whittaker M. Plasma cholinesterase variants and the anaesthetist. Anaesthesia 1980;35:174-97.

9 Dean G. The porphyrias. London: Pitman Medical, 1972.

10 Jenkins T, Nicholls E, Gordon E, Mendelsohn D, Seftel HC, Andrew MJA. Familial hypercholesterolaemia-a common genetic disorder in the Afrikaans population. $S$ Afr Med $J$ 1980;57:943-7.

"Kalow W, Lindsay HA. A comparison of optical and manometric methods for the assay of human serum cholinesterase. Can J Biochem Physiol 1955;33:568-74.

12 Kalow W, Genest K. A method for the detection of atypical forms of human serum cholinesterase. Determination of dibucaine numbers. Can J Biochem Physiol 1957;35:339-46.
${ }^{13}$ Harris H, Whittaker M. Differential inhibition of human serum cholinesterase with fluoride: recognition of two new phenotypes. Nature 1961;191:496-8.

14 Zsigmond EK, Flynn KB, Kothary SP. Improved method for the identification of the fluoride-resistant plasmacholinesterase genotypes. Biochem Genet 1980;18:861-7.

15 Stern J, Lewis WHP. Serum esterase in mongolism. J Ment Defic Res 1962;6:13-21.

16 Bark JE, Harris MJ, Firth M. Typing of the common PGM variants using isoelectric focusing - a new interpretation of the PGM system. J Forensic Sci Soc 1976;16:115-20.

17 Cohen JA, Oosterbaan RA, Jansz HS, Berends F. The active site of esterases. J Cell Comp Physiol 1959;54:231-44.

18 Jansz HS, Brons D, Warringa MGPJ. Chemical nature of the DFP-binding site of pseudocholinesterase. Biochim Biophys Acta 1959;34:573-5.

19 Laurell CB. Quantitative estimation of proteins by electrophoresis in agarose gel containing antibodies. Anal Biochem $1966 ; 15: 45-52$.

20 Altland K, Goedde HW, Held K, Jensen M, Munsch H, Solem E. New biochemical and immunological data on quantitative and qualitative variability of human pseudocholinesterase. Humangenetik 1971;14:56-60.

Correspondence and requests for reprints to Professor T Jenkins, Department of Human Genetics, The South African Institute for Medical Research, PO Box 1038, Hospital Street, Johannesburg 2000, South Africa. 